\title{
Commentary Acute stroke: we have the treatments and we have the evidence - we need to use them
}

\author{
Terence J Quinn, Jesse Dawson and Kennedy R Lees
}

Gardiner Institute of Cardiovascular and Medical Sciences, Western Infirmary, Dumbarton Road, Glasgow G11 6NT, UK

Corresponding author: Terence J Quinn, Tjq1t@clinmed.gla.ac.uk

Published: 17 April 2007

This article is online at http://ccforum.com/content/11/2/124

(C) 2007 BioMed Central Ltd
Critical Care 2007, 11:124 (doi:10.1186/cc5731)

blood pressure, clinical signs, duration and diabetes, on which the score is based.) This simple five-item instrument identifies high (8.1\%), medium (4.1\%) and low (1\%) 48-hour stroke risk. The score was robustly developed and validated in over 4,800 patients across diverse ethnic and socioeconomic groups.

Given the high initial risk for stroke, the best use of the score may be to identify patients who require immediate in-patient assessment. At the very least, by providing an assessment framework it should improve detection of the highest risk individuals but maybe improve diagnostic accuracy in suspected TIA; at present approximately $50 \%$ of referrals to diagnostic accuracy in TIA referrals is only 50\% [5]. Although the evidence base for hyper-early intervention in TIA is limited, we know that prompt carotid endarterectomy is effective [6], and acute stroke trials report reduced recurrence with antiplatelet treatment [7]. We assume that early initiation of secondary prevention in TIA will have similar effects, but we await the results of ongoing trials to address this definitively.

We should treat stroke with at least the same urgency as myocardial infarction; in fact, the time window for intervention is shorter. All patients with stroke symptoms require brain imaging to assist in diagnosis and to exclude treatable stroke mimics. We have suspected for many years that magnetic resonance imaging (MRI) is superior to computed tomography (CT) in this regard; Chalela and colleagues [2] have reported definitive proof. In a pragmatic trial of all referrals to an acute stroke service, initial MRI had a sensitivity of $83 \%$ in detecting acute ischaemic stroke; in contrast, the sensitivity with CT was only $16 \%$.

Traditionally, CT has been preferred because of perceived superior sensitivity in detecting intracerebral haemorrhage

$\mathrm{CT}=$ computed tomography; $\mathrm{ICH}=$ intracerebral haemorrhage; $\mathrm{MRI}=$ magnetic resonance imaging; rt-PA = recombinant tissue-plasminogen activator; TIA = transient ischaemic attack. 
Table 1

Summary of outcomes from SITS-MOST, meta-analysis of previous rt-PA trials and placebo arm

\begin{tabular}{|c|c|c|c|c|}
\hline & $\begin{array}{l}\text { Mortality } \\
\text { (at } 3 / 12 \text { ) }\end{array}$ & $\begin{array}{l}\text { Independence } \\
\text { (at 3/12) }\end{array}$ & $\begin{array}{l}\text { Symptomatic ICH } \\
(\text { per SITS-MOST)a }\end{array}$ & $\begin{array}{l}\text { Symptomatic } \mathrm{ICH} \\
\text { (per previous trials) }^{\mathrm{b}}\end{array}$ \\
\hline Trials & $17.3 \%$ & $49 \%$ & $N / A$ & $8.6 \%$ \\
\hline SITS-MOST & $11.3 \%$ & $54.8 \%$ & $1.7 \%$ & $7.3 \%$ \\
\hline Placebo & $18.4 \%$ & $30.2 \%$ & N/A & $1.9 \%$ \\
\hline
\end{tabular}

aBleed large enough to cause symptoms and accompanying neurological deterioration. bAny bleed with any alteration in neurological status, regardless of severity. rt-PA, recombinant tissue-plasminogen activator; SITS-MOST, Safe Implementation of Thrombolysis in Stroke Monitoring Study.

(ICH), better (but by no means acceptable) availability and concerns regarding practicalities of emergency MRI scanning. In their study, Chalela and coworkers [2] demonstrated equal ability of MRI to detect ICH in a real-time acute setting. A strong case can now be made for 24-hour access to MRI in all stroke centres. This requires investment; we note with pessimism that many UK centres still struggle to achieve national targets of CT scanning within 24 hours of ictus [8].

Consider the following scenario. sing MRI, a diagnosis of ischaemic stroke has been made for your patient. If this were myocardial infarct, thrombolytic therapy - with a number needed to treat of approximately 30 to avoid one death [9] would be instituted. Imagine if a similar treatment were available for acute ischaemic stroke but that the number needed to treat to reduce disability was only three. Such a treatment is available. We have known for more than a decade that intravenous recombinant tissue-plasminogen activator (rt-PA) is effective if administered within 3 hours of stroke onset [10] and a recent meta-analysis has confirmed efficacy [11] (Table 1).

There is of course a real and important risk for $\mathrm{ICH}$ with rt-PA. As such it was a condition of the European licence that a comprehensive monitoring study be performed (the SITSMOST [Safe Implementation of Thrombolysis in StrokeMonitoring Study]) [3]. This multicentre international study, including 6,483 patients across 285 centres, confirmed a high rate of good outcomes and allayed fears of frequent $\mathrm{ICH}$ (Table 1).

The SITS-MOST population and definition of haemorrhage demand some consideration. Only patients treated within the strict terms of the European licence were studied, and so patients with any of the following were excluded: age greater than 80 years, severe stroke, anticoagulation, history of diabetes and previous stroke. A substantial number of patients treated with rt-PA do not satisfy these criteria, and similar data on their outcomes would be of value. Symptomatic $\mathrm{ICH}$ was defined as haemorrhage involving $30 \%$ or more of infarct volume with objective clinical deterioration [3]. Although this is a different definition to that used in the original trials, it is arguably more meaningful. Previous definitions of symptomatic $\mathrm{ICH}$ included patients with minor bleeds or no measurable neurological sequelea. However, even these generously defined events were less common in routine practice than in the previous trials (Table 1 ).

An important finding in SITS-MOST [3] is that outcomes were similar regardless of the experience of the centre (although all were designated acute stroke centres), implying that thrombolytic therapy should now be more widely used. There is a long way to go; currently fewer than $5 \%$ of eligible patients in Europe receive thrombolytic therapy.

All stroke patients, whether they are treated with rt-PA or not, should be offered a further evidence-based intervention, namely specialist stroke unit admission. A systematic review has demonstrated consistent survival advantages of stroke units in addition to their rehabilitation role [12]. To date, studies provide little guidance on timing of admission and long-term benefits. The PROSIT (Project on Stroke Services in Italy) [4] observational study goes some way to addressing this shortfall. Acute (within 48 hours) admission to a dedicated stroke unit was associated with improved survival and functional outcome; benefits persisted at long-term follow up.

In the PROSIT study [4] a loose definition of stroke unit care was used. In extensive subgroup analysis, no single element of stroke unit care was convincingly linked to improved outcomes. The study was underpowered to address this issue, but it remains likely that a stroke unit is 'greater than the sum of its parts', with the individual components of care working synergistically. Our limited understanding of why stroke units work should not defer us from making use of this evidence-based intervention. The number of hospitals in PROSIT that offered dedicated stroke unit care is disappointing (30 out of 260 hospitals) and emphasizes how much further we have to go to improve stroke patient care in Europe. Surprisingly, patients admitted to centres with stroke units did better even if they were not admitted to the specialist ward. Perhaps simply having an enthusiastic stroke team within a centre has knock-on effects on other staff and practices. 
A theme across all of the reports in this Lancet collection is that evidence-based effective management of acute stroke is possible but implementation will require changes in attitudes and infrastructures. Our challenge is to promote utilization of proven therapies while developing novel ones. We encourage future generations of enthusiasts to help us take on this challenge.

\section{Competing interests}

The authors declare no relevant competing interests in relation to this work. KRL is a named author on the SITSMOST paper, and chaired the independent data monitoring committees for the ECASS III and DIAS trials of thrombolysis in stroke.

\section{References}

1. Johnston SC, Rothwell PF, Nguyen-huynh MN, Giles MF, Elkins JS, Bernstein AL, Sidney S: Validation and refinement of scores to predict very early stroke risk after transient ischaemic attack. Lancet 2007, 369:283-292.

2. Chalela JA, Kidwell CS, Nentwich LM, Luby M, Butman JA, Demchuk AM, Hill MD, Patronas N, Latour L, Warach S: Magnetic resonance imaging and computed tomography in emergency assessment of patients with suspected acute stroke: a prospective comparison. Lancet 2007, 369:293-298.

3. Wahlgren N, Ahmed N, Davalos A, Ford GA, Grond M, Hacke W, Hennerici MG, Kaste M, Kuelkens S, Larrue V, et al., for the SITSMOST investigators: Thrombolysis with alteplase for acute ischaemic stroke in the Safe Implementation of Thrombolysis in Stroke - Monitoring Study (SITS-MOST): an observational study. Lancet 2007, 369:275-282.

4. Candelise L, Gattinoni M, Bersano A, Micieli G, Sterzi R, Morabito A, on behalf of the PROSIT Study Group: Stroke-unit care for acute stroke patients: an observational follow-up study. Lancet 2007, 369:299-305.

5. Goldstein LB, Simel DL: Is this patient having a stroke? JAMA 2005, 293:2391-2402.

6. North American Symptomatic Carotid Endarterectomy Trial Collaborators: Beneficial effect of carotid endarterectomy in symptomatic patients with high-grade carotid stenosis. $N$ Engl J Med 1991, 325:445-453.

7. International Stroke Trial Collaborative Group: The international stroke trial (IST): a randomised trial of aspirin, subcutaneous heparin, both, or neither among 19435 patients with acute ischaemic stroke. Lancet 1997, 349:1569-1581.

8. Royal College of Physicians: National Clinical Guidelines for Stroke. London, UK: Royal College of Physicians; 2004.

9. Menon V, Harrington RA, Hochman JS, Cannon CP, Goodman SD, Wilcox RG, Schunemann HJ, Ohman EM: Thrombolysis and adjunctive therapy in acute myocardial infarction: The Seventh ACCP Conference on Antithrombotic and Thrombolytic Therapy. Chest 2004, Suppl 3:549-575.

10. The National Institute of Neurological Disorders and Stroke rt-PA study group: Tissue plasminogen activator for acute stroke. $N$ Engl J Med 1995, 333:1581-1587.

11. Hacke W, Donnan G, Fieschi C, Kaste M, von Kummer R, Broderick JP, Brott T, Frankel M, Grotta JC, Haley EC Jr, et al.: Association of outcome with early stroke treatment: Pooled analysis of ATLANTIS, ECASS, and NINDS rt-PA stroke trials. Lancet 2004, 363:768-744.

12. Stroke Unit Trialist' Collaboration: Organised inpatient (stroke unit) care for stroke (Cochrane Review). Cochrane Database Syst Rev 2002, 1:CD000197. 